\title{
Advantage of a precurved fenestrated endograft for aortic arch disease: Simplified arch aneurysm treatment in Japan 2010 and 2011
}

\author{
Yoshihiko Yokoi, MD, Takashi Azuma, MD, and Kenji Yamazaki, MD, PhD
}

Objective: We evaluated the results of our previous study investigating a precurved fenestrated endograft treatment for thoracic aortic aneurysms and aortic dissection extended to the aortic arch.

\begin{abstract}
Methods: From February 2010 to December 2011 at 35 Japanese centers, 383 patients (mean age, $75.7 \pm 9.4$ years) who required stent-graft landing in the aortic arch were treated with a precurved fenestrated endograft. The device has 19 3-dimensional curved stent skeleton types similar to aortic arch configurations and 8 graft fenestration types and is 24 to $44 \mathrm{~mm}$ in diameter and 16 to $20 \mathrm{~cm}$ long. The endografts were fabricated according to preoperative 3-dimensional computed tomographic images.

Results: Technical and initial successes were achieved in 380 and 364 cases, respectively. Device proximal end was at zones 0 to 2 in 363,15, and 2 patients, respectively. Lesions' proximal end ranged from zone 0 to 3 in 16 , 125,195 , and 44 patients, respectively. The mean operative and fluoroscopic times were $161 \pm 76$ and $26 \pm 13$ min, respectively. The complications included stroke (7 patients), permanent paralysis (3), and perioperative death (6). No branch occlusion or proximal migration of the device occurred during follow-up.

Conclusions: A precurved fenestrated endograft for endovascular repair in aortic arch disease rendered catheter manipulation simple and minimized operative complication risks. Although most patients had inadequate proximal landing zone and severely angled complex configuration, low mortality and morbidity and satisfactory clinical success were early outcomes, suggesting that this simplified treatment may be effective for aortic arch disease. (J Thorac Cardiovasc Surg 2013;145:S103-9)
\end{abstract}

As a less-invasive treatment, thoracic endovascular aortic repair (TEVAR) has emerged over the last decade. TEVAR for the descending thoracic aorta provides acceptable midterm morbidity and mortality. ${ }^{1,2}$ For aortic arch disease, however, some challenges that relate to its angulated morphologic features and the involvement of supra-aortic branches still remain. In the mid-2000s in Japan, the precurved fenestrated endograft Najuta (Kawasumi Lab, Inc, Tokyo, Japan) was developed to achieve good conformability and to extend the proximal landing zone. The multicenter clinical trial for approval by the Japanese Ministry of Health, Labor, and Welfare was conducted, with feasible results, in 2008 and 2009. In 2010, the multicenter clinical study commenced in 35 Japanese hospitals with the latest version of the Najuta graft, which is evolving continuously. The aim of this study was to evaluate the results of our previous study on endovascular treatment with a precurved

\footnotetext{
From the Department of Cardiovascular Surgery, Tokyo Women's Medical University, Tokyo, Japan.

Disclosures: Drs Yokoi, Azuma, and Yamazaki have nothing to disclose with regard to commercial support.

Read at The American Association for Thoracic Surgery Aortic Symposium, New York, New York, April 26-27, 2012.

Received for publication April 23, 2012; revisions received Sept 13, 2012; accepted for publication Nov 28, 2012.

Address for reprints: Yoshihiko Yokoi, MD, Department of Cardiovascular Surgery, Tokyo Women's Medical University, 8-1 Kawada, Shinjuku, Tokyo 162-8666, Japan (E-mail: kappa1231fumi@gmail.com).

$0022-5223 / \$ 36.00$

Copyright (c) 2013 by The American Association for Thoracic Surgery

http://dx.doi.org/10.1016/j.jtcvs.2012.11.058
}

fenestrated endograft for aortic arch disease and to explain the advantages and limitations of this device.

\section{MATERIALS AND METHODS \\ Patients}

From January 2010 to December 2011, a total of 383 patients at 35 Japanese centers who required stent-graft landing in the aortic arch underwent endovascular repair with a fenestrated endograft (clinical use of this device was approved by the individual institutional review board of each hospital). There were 329 men and 54 women (mean age, $75.69 \pm 9.42$ years; range, 23-93 years). All the patients were considered to have serious risk factors for open surgical repair and also to be ineligible for endovascular repair with commercially available devices because of an inadequate proximal landing zone. Of the patients, 332 had a degenerative aneurysm, 44 had an aortic dissection, 5 had a traumatic transection of the aortic isthmus, and 2 had a patent ductus arteriosus with congestive heart failure.

\section{Anatomic Indications}

All the patients underwent preoperative contrast-enhanced multilayered computed tomographic (CT) scans to assess the feasibility of endovascular repair, sizing of the endograft, and implantation strategy. The aortic arch configuration, including angulation and the location of branches and the proximal sealing zone of the endograft, was evaluated by 3-dimensional (3D) reconstruction with volume rendering of the CT data.

The anatomic exclusion criteria for endovascular aortic arch repair with precurved fenestrated endograft were (1) proximal or distal landing zone diameter greater than $42 \mathrm{~mm}$; (2) all supra-aortic branches involved in the aneurysmal wall; and (3) prohibitive occlusive disease, tortuosity, or calcification of intended access vessels and angulation of the aorta that would preclude advancement of the introduction system. In addition, an adequate proximal sealing zone was required between the supra-aortic 


\section{Abbreviations and Acronyms}

$$
\begin{array}{ll}
\text { 3D } & =3 \text {-dimensional } \\
\text { CT } & =\text { computed tomographic } \\
\text { LSA } & =\text { left subclavian artery } \\
\text { TEVAR } & =\text { thoracic endovascular repair }
\end{array}
$$

branches and the lesion on the aortic wall. The minimum length of that zone depended on the morphology of the pathologic aortic arch (Figure 1).

\section{Stent-Graft}

A precurved fenestrated endograft was customized for each patient. This device has 19 types of 3D curved stent skeletons and 8 types of graft fenestrations for arch vessels. Those types of differently formed stent skeletons and graft fenestrations were designed by analyzing more than 1000 clinical cases of aortic arch endografting with a custom-made device. According to preoperative 3D CT, the endograft suitable for each patient was fabricated by selecting from the available stent skeletons and graft fenestrations. The method of device design and the implantation strategy are represented in Figures 2 and 3.

The endograft ranged from 24 to $44 \mathrm{~mm}$ in diameter and 16 to $20 \mathrm{~cm}$ in length. Commercially available devices (Excluder TAG; W.L. Gore \& Associates, Inc, Flagstaff, Ariz; and Zenith TX2; Cook Inc, Bloomington, Ind) were used for the descending portion of the lesion as necessary.

\section{Delivery System}

This device has an original stabilizing system composed of rigid fixation on the proximal tip and a traction suture to shrink the proximal end of the stent-graft, for exact endograft positioning in the aortic arch under normal blood pressure. During the deployment, the proximal end of the stent-graft is gradually opened, and the second and third units of the Z-stent are landed at the aortic wall first. The endograft is still amenable to fine adjustment at this time. By making use of blood flow, the endograft can be pushed up to the greater curvature to achieve good conformability to the aortic arch configuration, and the graft material is expanded at the proximal landing zone without touch-up ballooning. The details of this stabilizing system are explained in Figure 4.

To facilitate safe access to the ascending aorta, the delivery sheath has a short, soft proximal tip and 3 types of precurved shapes similar to the aortic arch. The outer diameter of the sheaths ranged from $21 \mathrm{~F}$ to $23 \mathrm{~F}$ in the proximal portion and tightened to $18 \mathrm{~F}$ at the distal end. This characteristic form may assist precise deployment when the patient has a severely diseased access route.

\section{Procedure}

In 380 of the 383 patients, the endovascular procedure was performed with general anesthesia, whereas epidural anesthesia was used in 3 patients. The common femoral artery, exposed through an inguinal incision, was mainly used as the access vessel. A "tug-of-wire" method was the preferred guiding technique used to stretch this precurved device in the access route. The precurved fenestrated endograft was deployed in the aortic arch under fluoroscopic guidance without additional circulatory support (ie, without adenosine-induced cardiac arrest and rapid pacing). Device rotation was automatically controlled by the precurved shape of the stent-graft and the dedicated stabilizing mechanism. Baseline digital subtraction angiography was performed before and after stent-graft deployment to confirm the proper positioning of the device and complete exclusion of the lesion (Figure 4).

Postdeployment balloon dilatation was performed selectively. Left subclavian artery (LSA) revascularization was only undertaken in selected patients. ${ }^{3,4}$ Our selection criteria were (1) the coronary circulation supplied by the LSA through the left internal thoracic artery, (2) an inadequate contralateral vertebral artery, and (3) a high-risk for spinal cord ischemia.

\section{RESULTS}

The 383 patients who required stent-graft landing in the aortic arch at zones 0 to 2 (the aortic arch map proposed by Mitchell and colleagues ${ }^{5}$; Figure 5) were treated with the precurved fenestrated endograft. The mean proximal aortic diameter was $33.75 \pm 3.7 \mathrm{~mm}$. The mean length of the pathologic aortic arch was $79 \pm 57 \mathrm{~mm}$ (with the exception of aortic dissection of the double-barrel type). The mean proximal sealing zone length was $14.3 \pm 5.3 \mathrm{~mm}$. Technical success, defined as successful deployment in the intended location of the aortic arch, was achieved in 380 patients $(99.2 \%)$, whereas in 3 patients the endograft could not reach the thoracic lesion because of access vessel inferiority. The proximal end of the device was placed at zone 0 in 363 patients, zone 1 in 15, and zone 2 in 2 . The proximal end of the lesion originated in zone 0 in 16 patients, zone 1 in 125, zone 2 in 195, and zone 3 in 44 (Figure 5).

Initial success, defined as absence of type I or III endoleaks on postoperative CT scan, was obtained in 364 cases $(95.8 \%)$. The 30-day mortality was $1.6 \%$ (1 multiple embolism, 1 fatal stroke, 1 ascending dissection, 1 respiratory failure, 1 aneurysm rupture with type I endoleaks, and 1 unidentified cause with impending rupture). Cerebrovascular accident occurred in 7 patients $(1.8 \%)$ and permanent paralysis in $3(0.8 \%)$. Ascending aortic dissection occurred in 3 patients: all had previous aortic dissection and a large-diameter $(\geq 40 \mathrm{~mm})$ ascending aorta. One stentgraft collapse occurred 4 days after the procedure in a patient with a small and tightly curved aortic arch. Three open surgical replacements were performed, 2 in patients with dissections and 1 in the patient with the stent-graft collapse. Unanticipated chimney stenting ${ }^{6}$ was required to preserve perfusion of supra-aortic trunks in 3 patients, including 1 with a minor stoke.

Intentional coverage of the LSA was carried out in 298 patients with 17 simultaneous revascularizations. The mean operative time was $161 \pm 76 \mathrm{~min}(146 \pm 63 \mathrm{~min}$ without LSA revascularization), and the mean fluoroscopic time was $26 \pm 13 \mathrm{~min}$.

\section{DISCUSSION}

A large number of thoracic pathologic conditions involve the aortic arch, and operative approaches for aortic arch disease have therefore evolved continuously during the past 20 years. There have been significant developments in the fields of surgical techniques and extracorporeal circulation; nevertheless, conventional open aortic arch replacement is still associated with substantial morbidity and mortality.,

In contrast, the endovascular approach has emerged during the past decade as a valuable less-invasive treatment for 


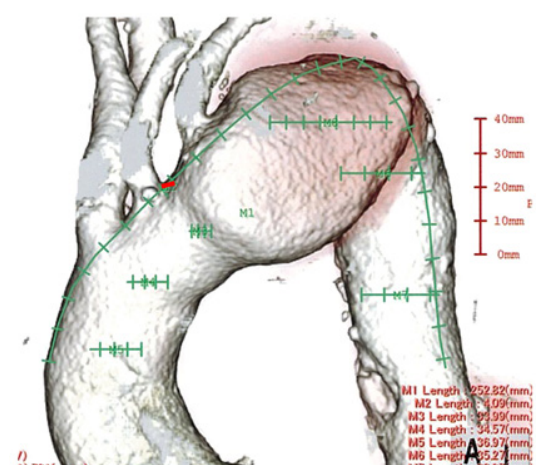

A1

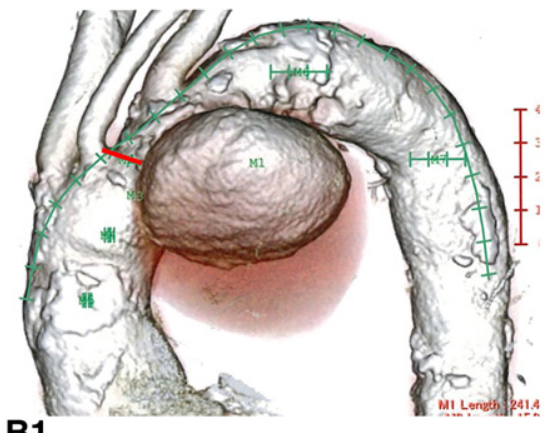

B1

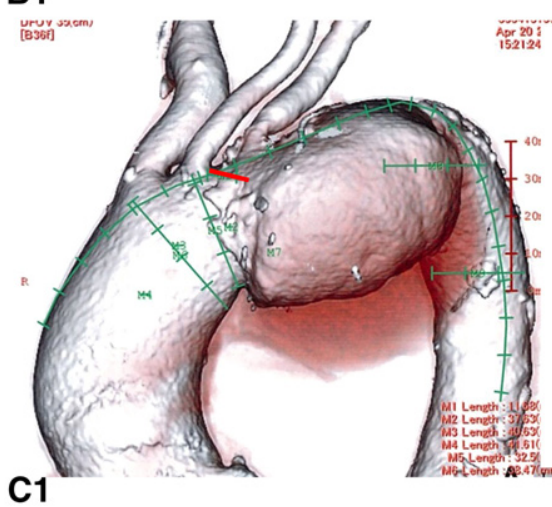

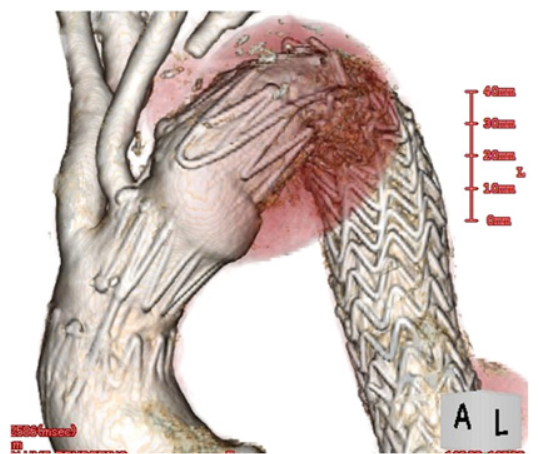

A2

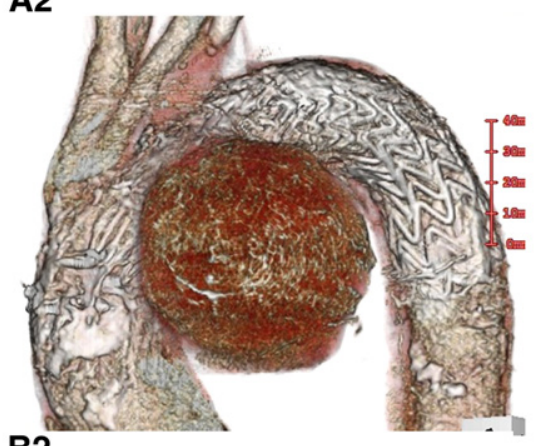

B2

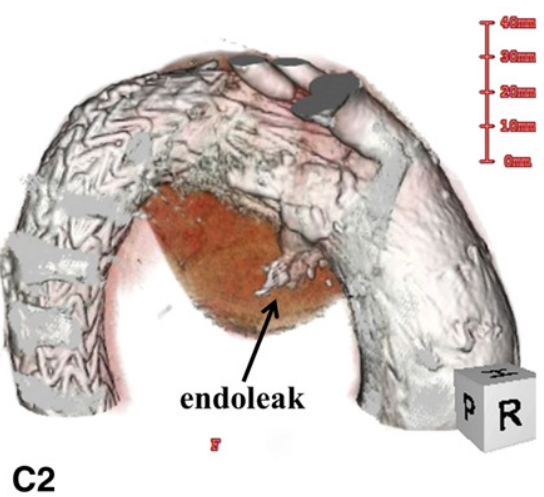

FIGURE 1. A1, Preoperative 3-dimensional computed tomography ( $3 D-C T)$ of a zone 1 aortic arch aneurysm with appropriate proximal landing zone and short proximal sealing length (red line). A2, Postoperative 3-dimensional computed tomography with complete exclusion of the aortic arch aneurysm demonstrates that the appropriate proximal landing zone provides good results. B1, Preoperative 3-dimensional computed tomography of a zone 1 aortic arch aneurysm with substantial proximal sealing length (red line) and inadequate proximal landing zone. B2, Postoperative 3-dimensional computed tomography with complete exclusion of the aortic arch aneurysm demonstrates that the substantial proximal sealing length provides feasible results. C1, Preoperative 3-dimensional computed tomography of a zone 1 aortic arch aneurysm with short proximal sealing length (red line) and inadequate (proximal diameter $>40$ $\mathrm{mm}$ ) proximal landing zone. C2, Postoperative 3-dimensional computed tomography with type I endoleak (arrow) demonstrates blood flow into the lesion through the posterior side of the stent-graft, causing insufficient contact between fenestrations and aortic wall.

descending thoracic aortic disease. Although some devices that have recently been developed (eg, TX2 Pro-Form, c-TAG) exhibit enhanced conformability to a curved configuration, the anatomic indications for aortic arch disease are still limited by angulated complex morphological feature and the involvement of supra-aortic branches. Hybrid procedures involving open surgical debranching (which is performed to provide an appropriate proximal landing zone for the stent-graft and to preserve perfusion to the supra-aortic trunks) followed by endovascular repair have therefore been applied to patients who are poor surgical candidates because of serious comorbidities. Recent reports have demonstrated the feasibility of aortic arch hybrid repair. ${ }^{9-12}$

It is possible that an entirely endovascular approach with a branched or fenestrated endograft would limit the operative morbidity and mortality associated with the other options; however, few studies ${ }^{13,14}$ have reported the use of branched endografts for aortic arch disease. This is presumably because of the difficulty involved in catheter manipulation in the aortic arch, which increases the risk of embolic 

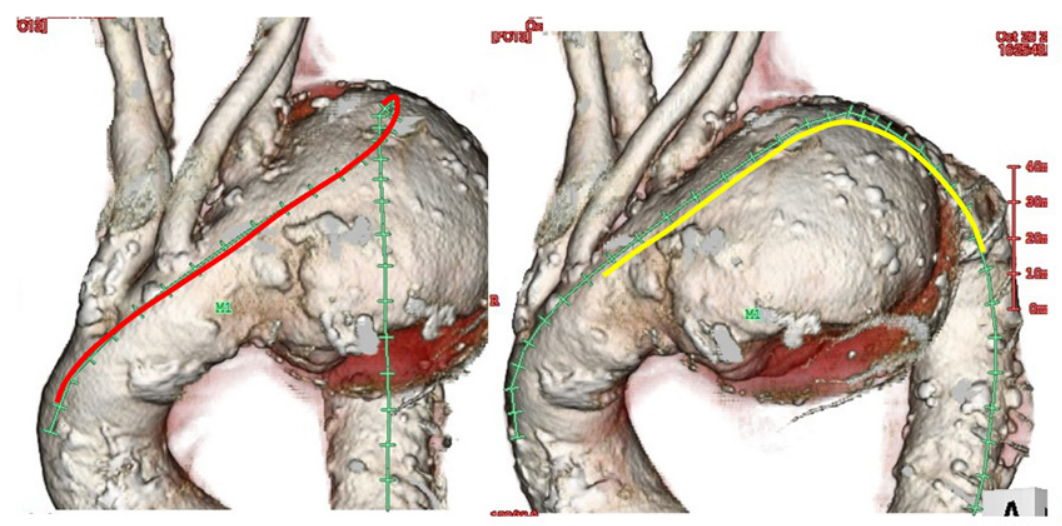

A

B
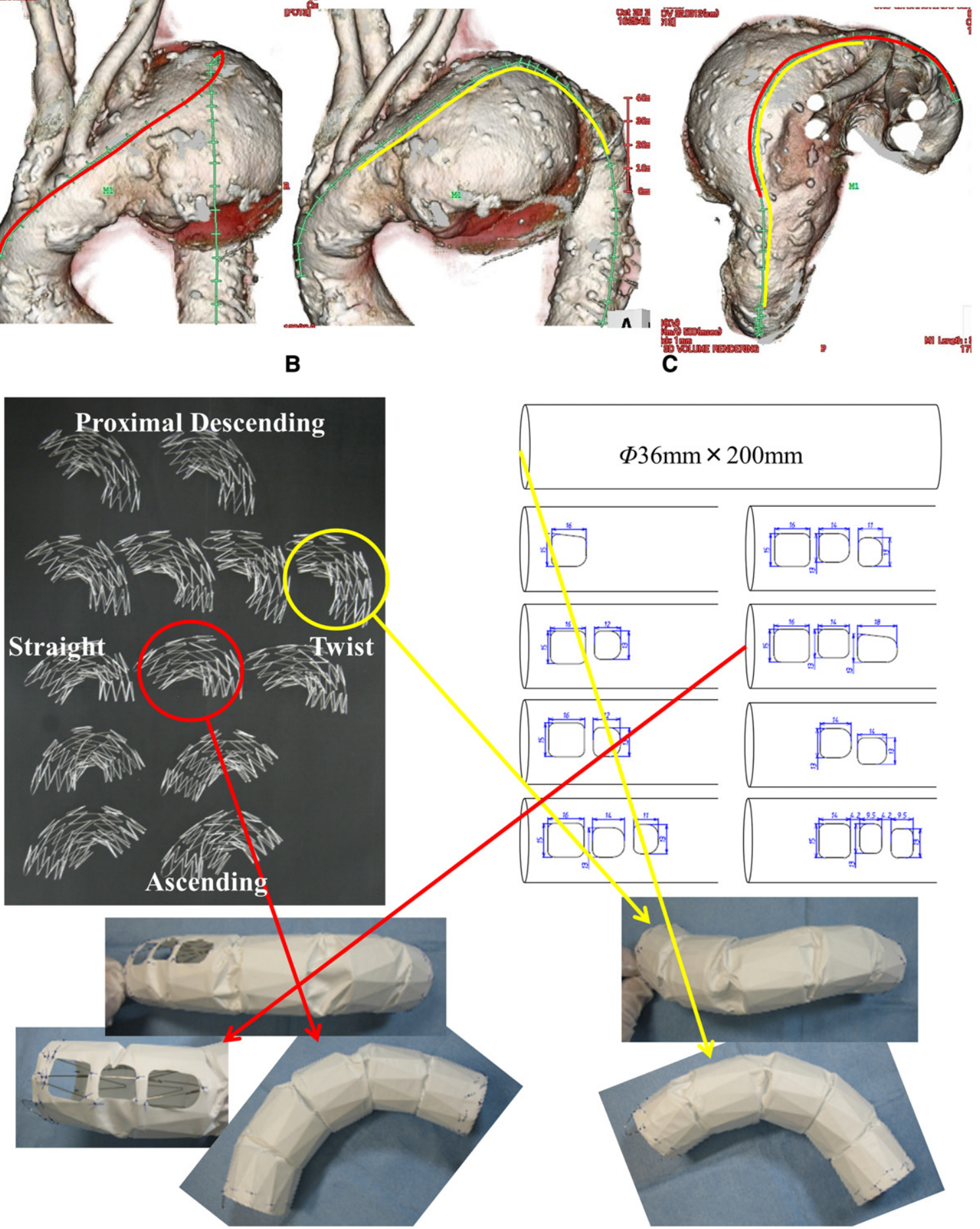

D
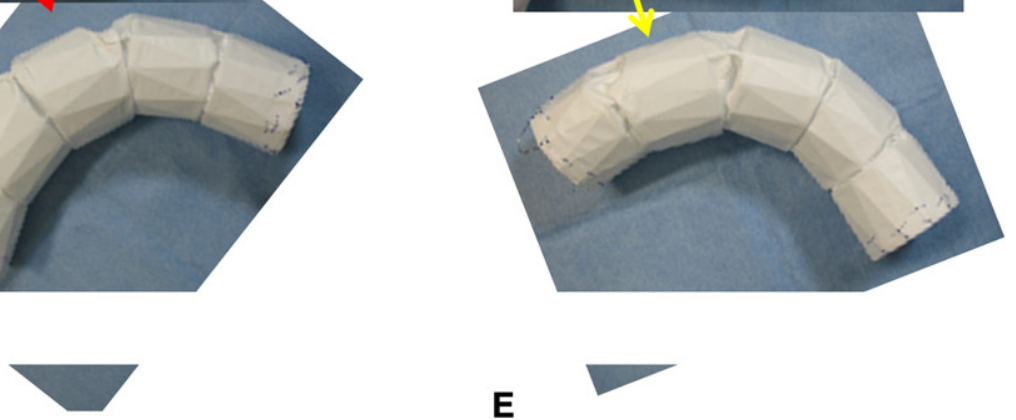

E

FIGURE 2. A, Preoperative 3-dimensional computed tomographic ( $3 D-C T)$ anteroposterior view of an aortic arch aneurysm with guiding red line used to design proximal fenestrated stent-graft. B, Preoperative 3-dimensional computed tomographic left anterior oblique $30^{\circ}$ view with guiding yellow line used to design distal stent-graft. C, Head-to-foot view demonstrates complex configuration of the aortic arch aneurysm. D, The precurved fenestrated endograft (proximal stent-graft) was fabricated by selecting from these kinds of 3-dimensional curved stainless stent skeleton and fenestrated expanded polytetrafluoroethylene grafts $(e-P T F E)$. E, Distal stent-graft had a twisted formation similar to complicated configuration of this patient. 


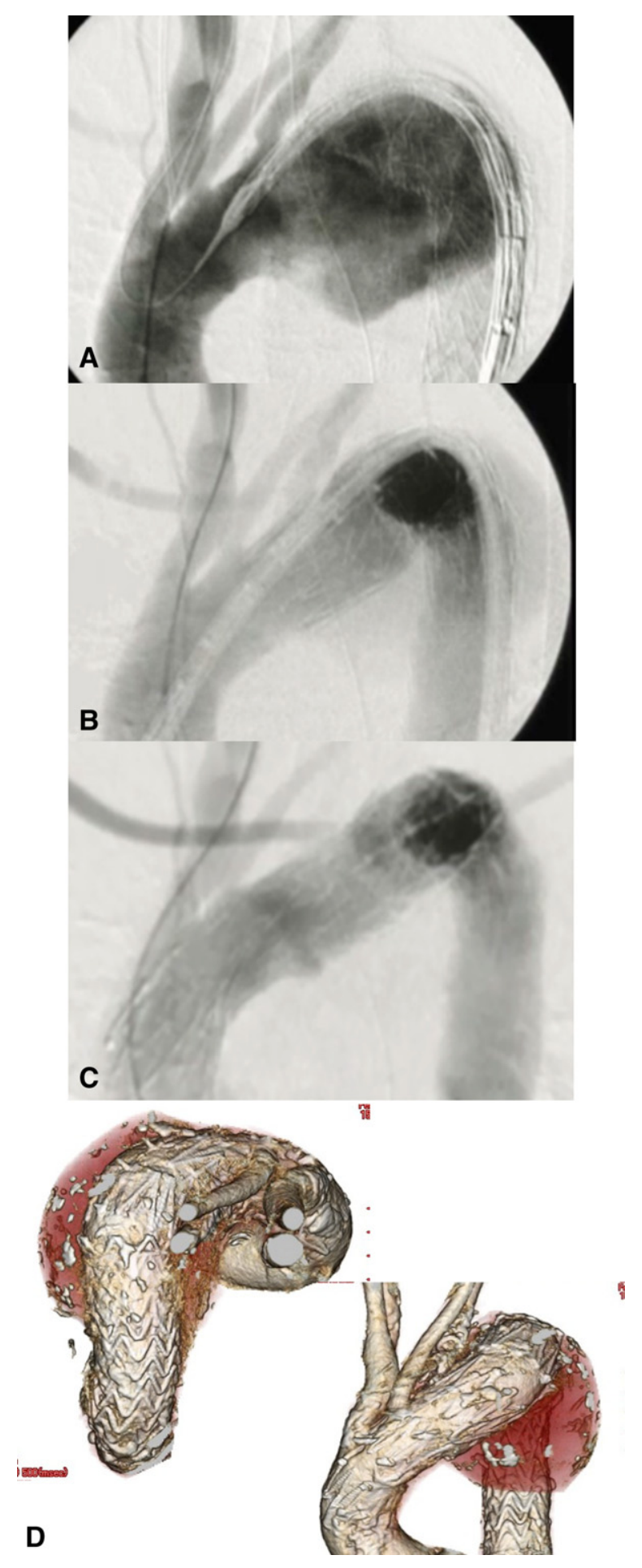

FIGURE 3. Implantation strategy. A, Intraoperative digital subtraction angiography before deployment of distal device. B, Intraoperative digital subtraction angiography (DSA) after deployment of distal stent-graft, which prevented migration of the proximal graft. C, Intraoperative digital subtraction angiography after deployment of the proximal stent-graft shows absence of endoleak. D, Postoperative 3-dimensional computed tomography $(3 D-C T)$ demonstrates that this device has good conformability for the complicated configuration of this aortic arch aneurysm. stroke. In our study, the entirely endovascular procedure with a precurved fenestrated endograft simplified the manipulation required, decreasing the incidence of neurologic complications. Rotation of the device was controlled by its precurved shape, which was designed to be similar to the aortic arch configuration in each patient, and the fenestrations were automatically oriented toward the supra-aortic trunks. The short time required for operation and fluoroscopy proves that this procedure does not entail a complicated catheter technique. The high rate of clinical success demonstrates that this endograft technique provides an appropriate proximal landing zone across the supra-aortic trunks and yields good conformability to aortic arch angulations. Furthermore, a dedicated stabilizing mechanism provides precise endograft deployment without circulatory assistance (eg, circulatory arrest induced by a drug and rapid pacing) and minimizes contact between the supraaortic branch orifice and the ascending aortic wall. As a result, although most patients in this study had inadequate proximal landing zones and severely angled complex configurations, low mortality and morbidity and a satisfactory clinical success rate were achieved in the initial stage of the study.

Long-term effectiveness could not be determined in this early-stage study; however, the data from an earlier study with the previous generation of precurved fenestrated endografts reported by Kawaguchi and colleagues ${ }^{15}$ and indicate acceptable midterm outcomes. Furthermore, the results of the multicenter clinical trial (endografts implanted from 2008 to 2009, awaiting approval from the Japanese Ministry of Health, Labor, and Welfare) confirmed midterm feasibility with absence of proximal migration and branch occlusion.

The aim of surgical therapy for aortic pathologies is prevention of aneurysm rupture, and the aim of the endovascular approach is to make that surgery less invasive and safer. The aim of our investigation is not only to extend anatomic indications for treatment but also to minimize operative risks and maintain the activity of daily life of our patients such that they can continue to function normally for a substantial time without surgical intervention. In the near future in Japan, patients with serious comorbidities (especially the elderly population) will be treated with this minimally invasive aortic repair technique, as will the patients at lower risk with anatomic indications.

With constant development of the device and endograft implant strategies, this simplified therapeutic method with a precurved fenestrated endograft has the potential to become one of the standard therapies for the treatment of aortic arch disease.

\section{CONCLUSIONS}

A simplified arch aneurysm treatment with a precurved fenestrated endograft represents a minimally invasive treatment for aortic arch disease. The acceptable clinical success and low incidences of stroke and early death, in conjunction 


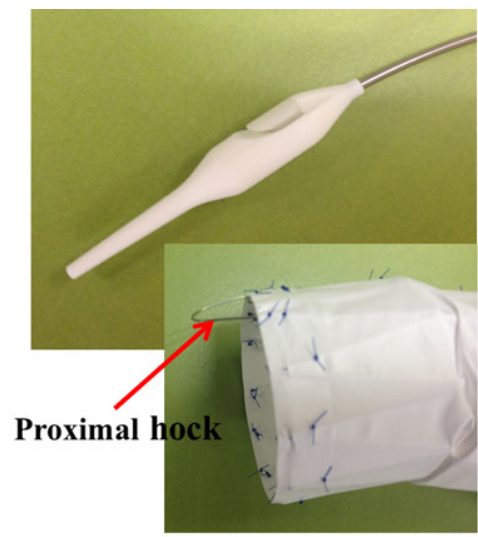

A

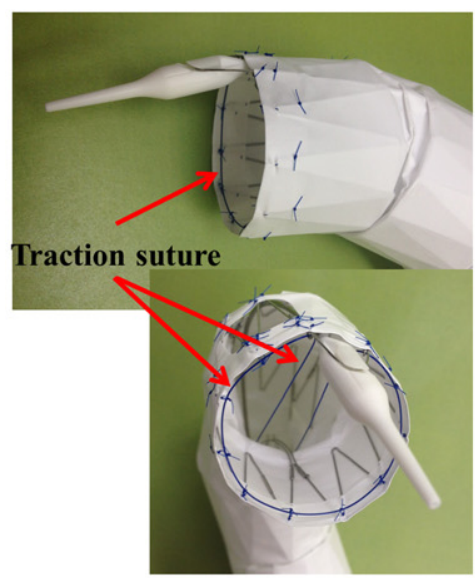

B

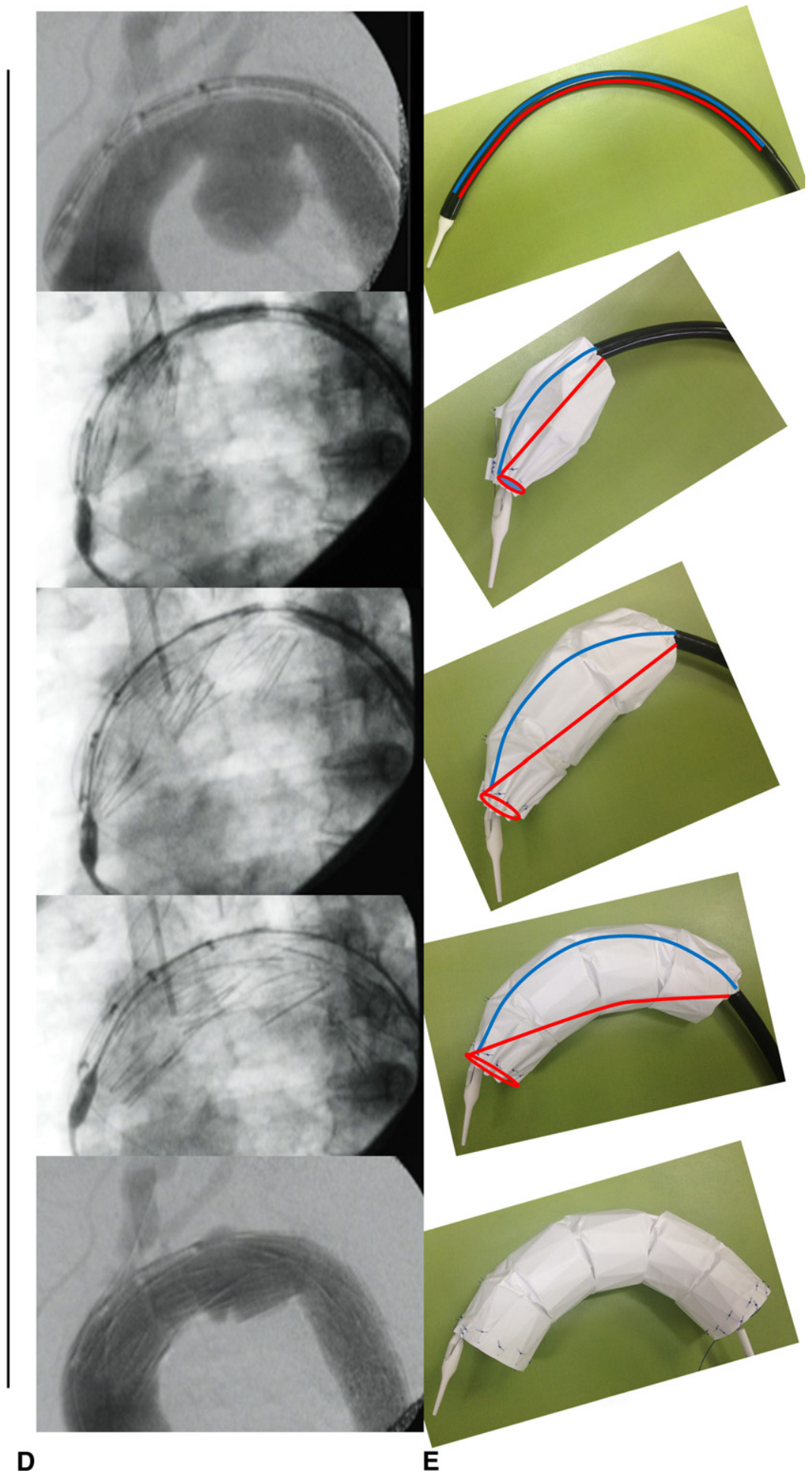

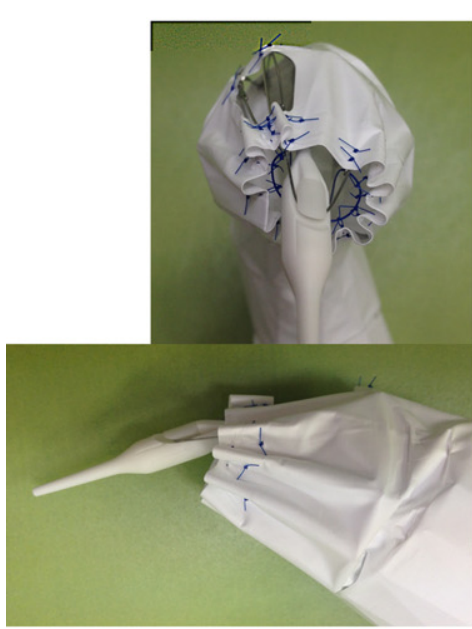

C
D

FIGURE 4. A, The proximal tip has a concavity for fixation (top), and the proximal end of the stent-graft has a stainless steel hock (bottom). B, The proximal end of the stent-graft is anchored to the tip (top), and the traction suture to shrink proximal end is fixed at distal end of the stent-graft (bottom). C, The proximal end of the stent-graft is shrunk by traction suture (top), and the proximal end of the device is pulled down to a smaller coverture (bottom). D, Predeployment digital subtraction angiographic (DSA) (top), intradeployment fluoroscopic (middle), and postdeployment digital subtraction angiographic (bottom) images demonstrate precise deployment and exhibit device behaviors during the deployment period. E, As the traction suture is gradually straightening during the stent-graft deployment, the proximal end of the stent-graft is gradually opening. 


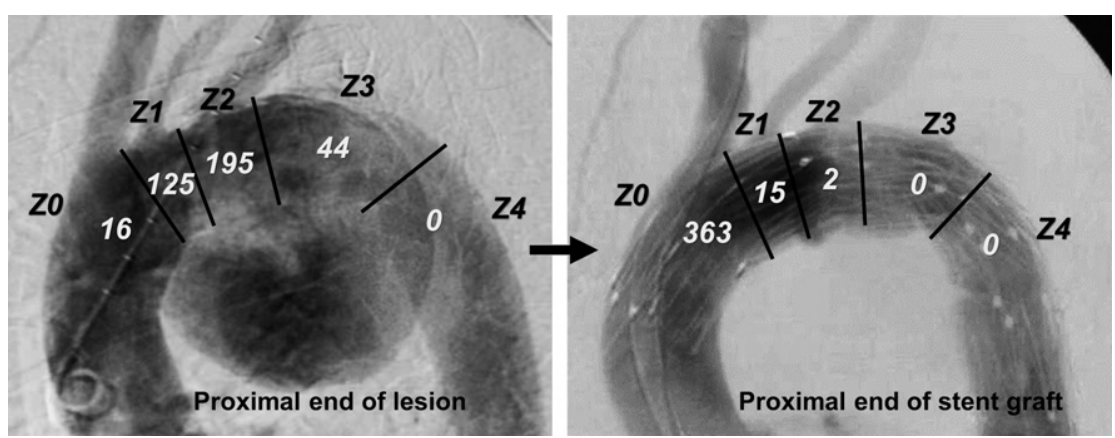

FIGURE 5. The numbers of patients for proximal ends of the lesion and the stent-graft in anatomic zone mapping.

with the endovascular repair attained with this device, suggest that it is potentially a valuable method for the treatment of aortic arch disease. Further evaluation and follow-up are still required, however, to determine the role that this endovascular approach will have in the future.

\section{References}

1. Bavaria JE, Appoo JJ, Makaroun MS, Verter J, Yu ZF, Mitchell RS, et al. Endovascular stent grafting versus open surgical repair of descending thoracic aortic aneurysms in low-risk patients: a multicenter comparative trial. J Thorac Cardiovasc Surg. 2007;133:369-77.

2. Yuri K, Yamaguchi A, Hori D, Shiraishi M, Nagano H, Adachi H, et al. Comparison between stent grafting and open surgery in thoracic aortic aneurysms. Jpn J Vasc Surg. 2010;19:51-6.

3. Melissano G, Civilini E, Bertoglio L, Setacci F, Chiesa R. Endovascular treatment of aortic arch aneurysms. Eur J Vasc Endovasc Surg. 2005;29: 131-8.

4. Schoder M, Grabenwöger M, Hölzenbein T, Cejna M, Ehrlich MP, Rand T, et al. Endovascular repair of the thoracic aorta necessitating anchoring of the stent graft across the arch vessels. J Thorac Cardiovasc Surg. 2006;131:380-7.

5. Mitchell RS, Ishimaru S, Ehrlich MP, Iwase T, Lauterjung L, Shimono T, et al. First International Summit on Thoracic Aortic Endografting: roundtable on thoracic aortic dissection as an indication for endografting. J Endovasc Ther. 2002; 9(Suppl 2):II98-105.

6. Criado FJ. A percutaneous technique for preservation of arch branch patency during thoracic endovascular aortic repair (TEVAR): retrograde catheterization and stenting. J Endovasc Ther. 2007;14:54-8.
7. Spielvogel D, Etz CD, Silovitz D, Lansman SL, Griepp RB. Aortic arch replacement with a trifurcated graft. Ann Thorac Surg. 2007;83:S791-5; discussion S824-31.

8. Toda K, Taniguchi K, Masai T, Takahashi T, Kuki S, Sawa Y. Arch aneurysm repair with long elephant trunk: a 10-year experience in 111 patients. Ann Thorac Surg. 2009;88:16-22.

9. Canaud L, Hireche K, Berthet JP, Branchereau P, Marty-Ané C, Alric P. Endovascular repair of aortic arch lesions in high-risk patients or after previous aortic surgery: midterm results. J Thorac Cardiovasc Surg. 2010;140:52-8.

10. Bavaria J, Milewski RK, Baker J, Moeller P, Szeto W, Pochettino A. Classic hybrid evolving approach to distal arch aneurysms: toward the zone zero solution. J Thorac Cardiovasc Surg. 2012;140(6 Suppl):S77-80; discussion S86-91.

11. Geisbüsch P, Kotelis D, Müller-Eschner M, Hyhlik-Dürr A, Böckler D. Complications after aortic arch hybrid repair. J Vasc Surg. 2011;53:935-41.

12. Ham SW, Chong T, Moos J, Rowe VL, Cohen RG, Cunningham MJ, et al. Arch and visceral/renal debranching combined with endovascular repair for thoracic and thoracoabdominal aortic aneurysms. J Vasc Surg. 2011;54:30-40; discussion 40-1.

13. Inoue K, Sato M, Iwase T, Yoshida Y, Tanaka T, Tamaki S, et al. Clinical endovascular placement of branched graft for type B aortic dissection. J Thorac Car diovasc Surg. 1996;112:1111-3.

14. Chuter TA, Schneider DB, Reilly LM, Lobo EP, Messina LM. Modular branched stent graft for endovascular repair of aortic arch aneurysm and dissection. $J$ Vasc Surg. 2003;38:859-63.

15. Kawaguchi S, Yokoi Y, Shimazaki T, Koide K, Matsumoto M, Shigematsu H. Thoracic endovascular aneurysm repair in Japan: experience with fenestrated stent grafts in the treatment of distal arch aneurysms. J Vasc Surg. 2008; 48(6 Suppl):24S-9S; discussion 29S. 